\title{
Erratum to: Singularity theorems and their consequences
}

\author{
José M. M. Senovilla
}

Published online: 13 May 2014

(C) Springer Science+Business Media New York 2014

\section{Erratum to: Gen Relativ Gravit (1998) 30:701-848 DOI 10.1023/A:1018801101244}

In the online version of this article, the bibliographic information given in the header and the copyright line in the footer of the title page are incorrect.

The correct bibliographic information should read:

General Relativity and Gravitation, Vol. 30, No. 5, 1998.

The correct copyright line should read:

0001-7701/ 98/ 0500-0701\$15.00/ 0 @ 1998 Plenum Publishing Corporation

The online version of the original article can be found under doi:10.1023/A:1018801101244. 